\title{
Phase I/II Study of Sorafenib in Combination with Hepatic Arterial Infusion Chemotherapy Using Low-Dose Cisplatin and 5-Fluorouracil
}

\author{
Kazuomi Ueshima ${ }^{a}$ Masatoshi Kudo ${ }^{a}$ Masatoshi Tanaka ${ }^{b}$ \\ Takashi Kumada $^{c}$ Hobyung Chung ${ }^{\text {a }}$ Satoru Hagiwara ${ }^{a}$ \\ Tatsuo Inoue ${ }^{a}$ Norihisa Yada ${ }^{a}$ Satoshi Kitai ${ }^{a}$ \\ aDepartment of Gastroenterology and Hepatology, Kinki University School of Medicine, Osaka, \\ bDepartment of Hepatology, Yokokura Hospital, Fukuoka, 'Department of Gastroenterology, Ogaki \\ Municipal Hospital, Gifu, Japan
}

\section{Key Words}

Cisplatin · Fluorouracil $\cdot$ Hepatic arterial infusion $\cdot$ Hepatocellular carcinoma $\cdot$ Sorafenib

\begin{abstract}
We conducted a phase I/II study in patients with advanced hepatocellular carcinoma (HCC) to determine the recommended dose, as well as the safety and efficacy, of combination therapy of sorafenib with hepatic arterial infusion chemotherapy (HAIC) using low dose cisplatin (CDDP) and 5-fluorouracil (5FU). Cohorts consisting of 3-6 patients with HCC received an escalated dose of CDDP and 5-FU until a maximum-tolerated dose was achieved. The treatment regimen was as follows: oral administration of sorafenib (400 mg twice daily for 28 days) combined with HAIC using CDDP (14-20 mg/m², on days 1 and 8$)$ and $5-F U ~\left(170-330 ~ m g / \mathrm{m}^{2}\right.$, continuously on days $1-5$ and 8-12) via an implanted catheter system). Each treatment cycle consisted of 28 days and three cycles of combination therapy. At the end of the first cycle, adverse events were evaluated and future dose escalation was determined. Eighteen patients with advanced HCC were enrolled. Dose-limiting toxicity was observed in two patients from cohort 1 (erythema multiforme and grade 4 thrombocytopenia) and in one patient from cohort 2 (erythema multiforme). Seven of the 18 patients achieved a partial response, seven showed stable disease, two were diagnosed as progressive disease, and two were not assessable. The response rate was $38.9 \%$ and the disease control rate was $77.8 \%$. The time-
\end{abstract}

Masatoshi Kudo, MD, PhD

Department of Gastroenterology and Hepatology,

Kinki University School of Medicine

377-1 Ono-Higashi, Osaka-Sayama, Osaka 589-8511 (Japan)

Tel. +81 723660221 Ext. 3525, E-Mail m-kudo@med.kindai.ac.jp

KARGER 125 
to-progression was 9.7 months and the 1 -year survival rate was $88.2 \%$. Oral administration of $400 \mathrm{mg}$ of sorafenib twice daily, $20 \mathrm{mg} / \mathrm{m}^{2}$ of intra-arterial infusion of CDDP, and 5-FU at $330 \mathrm{mg} / \mathrm{m}^{2}$ are the recommended doses for combination therapy, which was well tolerated and efficacious. This combination therapy may be a promising treatment for patients with advanced HCC. A large prospective randomized multicenter study (ClinicalTrials.gov Identifier NCT01214343) is ongoing.

Copyright $@ 2015$ S. Karger AG, Basel

\section{Introduction}

Hepatocellular carcinoma (HCC) is respectively the fifth and seventh most common cancer in men and women, and it is also the third leading cause of cancer-related death worldwide [1]. In Japan, almost 30,000 people die annually because of HCC, and 47,000 people were estimated to suffer from this type of cancer in 2010 [2]. HCC usually emerges from a background of liver cirrhosis and chronic hepatitis caused by viral hepatitis infection because chronic liver injury induces apoptosis and regeneration of hepatocytes and liver matrix remodeling. These conditions accelerate fibrogenesis and hepatocarcinogenesis [3].

A variety of treatments, such as resection [4, 5], radiofrequency ablation [6-8], transcatheter arterial chemoembolization (TACE) [9-11], and transplantation [12-14] have been performed for patients with HCC. The type of treatment is selected based on the tumor status and clinical condition of the patient $[15,16]$. Resection and radiofrequency ablation are selected for early stage-HCC as a curative treatment, and TACE is applied for intermediate stage patients. For locally advanced HCC with major vascular invasion or diffuse type HCC, hepatic arterial infusion chemotherapy (HAIC) is used to induce tumor shrinkage or regression of vascular invasion. However, HAIC is not commonly used worldwide because of a lack of evidence for survival benefit and the complicated management of the implanted catheter system. An advantage of HAIC is the delivery of a high concentration of antitumor agents to the target organ through the hepatic artery, which leads to effective antitumor activity of the agent with a minimal concentration entering the systemic circulation, thus reducing the incidence of adverse events (AE). In a prior study, the response rate (RR) of agents used for HAIC including cisplatin (CDDP) monotherapy and epirubicin hydrochloride monotherapy was $37 \%$ [17] and $15.1 \%$, respectively [18]. Combination chemotherapy, such as CDDP with 5-fluorouracil (5-FU) and etoposide with CDDP and 5-FU, have achieved a RR of between 14-44\% [19-25] and 46\% [26], respectively.

Sorafenib (Nexavar ${ }^{\circledR}$, Bayer HealthCare Pharmaceuticals) is a small molecule that inhibits the proliferation of cancer cells and tumor angiogenesis. It also enhances apoptosis by inhibiting Raf-1, B-Raf kinase and tyrosine kinase molecules in vascular endothelial growth factor receptors 1,2 , and 3 , in addition to platelet-derived growth factor receptor $\beta$ [27]. Sorafenib is the current standard therapy for advanced HCC worldwide, including Japan. Phase III randomized controlled trials have proven the survival benefit of sorafenib for patients with unresectable HCC $[28,29]$.

Interestingly, the antitumor effects of sorafenib are attributed to the induction of tumor dormancy rather than tumor shrinkage, which is in contrast to the tumor shrinkage effect of HAIC. Therefore, we considered that a combination of sorafenib with HAIC could be an ideal treatment for HCC. We conducted a phase I/II study to determine the recommended dose of sorafenib with HAIC for combination therapy and its efficacy and safety in patients with HCC. 


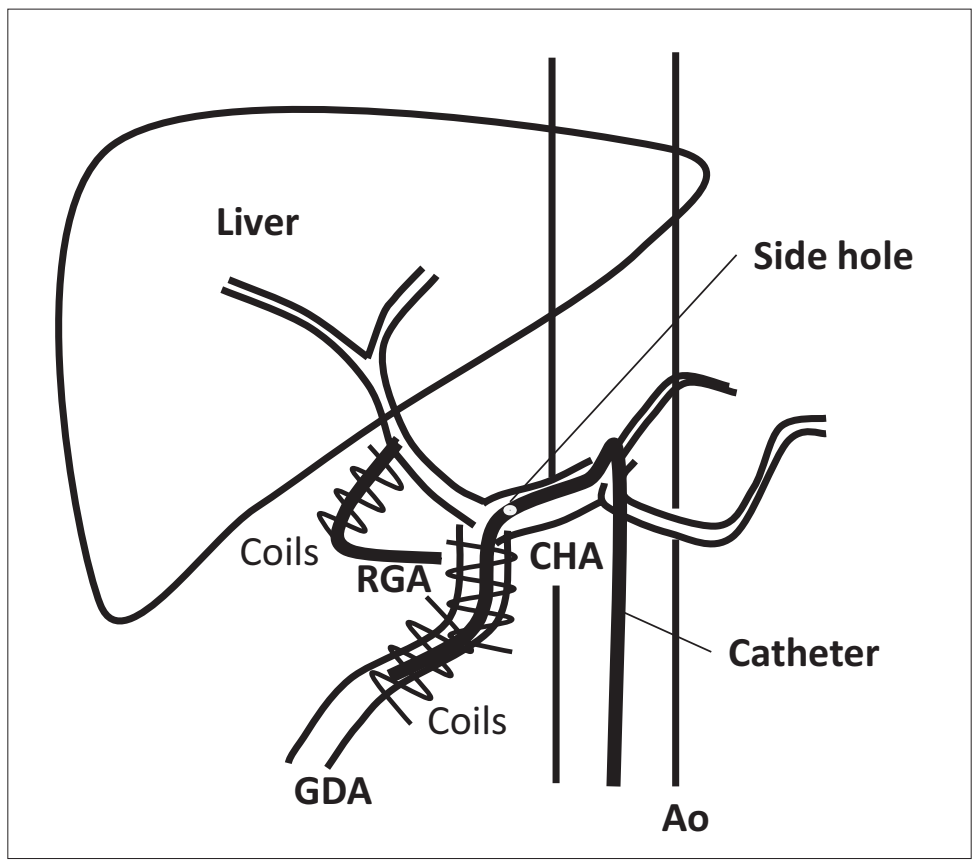

Fig. 1. Catheter placement.

$\mathrm{CHA}=$ common hepatic artery; GDA=gastroduodenal artery; Ao=abdominal aorta; Coils=metallic embolization coils.

\section{Patients and Methods}

\section{Patient Selection}

Eligible patients had proven HCC confirmed histologically from a biopsy, or by typical radiological findings on dynamic computed tomography (CT) or CT during hepatic arteriography/arterioportography. None of the patients were suitable for resection, local ablation therapy or TACE. The eligibility criteria included: age >20 years, an Eastern Cooperative Oncology Group (ECOG) performance status score of 1 or less, Child-Pugh liver function class A or B, a life expectancy of 12 weeks or more, adequate hematologic findings (defined as a platelet count $\geq 50,000$ per microliter, hemoglobin $\geq 8.5$ grams per deciliter, neutrophils $\geq 1,500$ per microliter and a prothrombin time international normalized ratio $\leq 2.3$, or a prothrombin time $\leq 6$ seconds above the control), adequate hepatic function (total bilirubin $\leq 2 \mathrm{mg}$ per deciliter, alanine aminotransferase (ALT) and aspartate aminotransferase (AST) $\leq 5$ times the upper limit of the normal range), and adequate renal function (serum creatinine $\leq 1.5$ times the upper limit of the normal range), and normal amylase levels ( $5 \mathrm{x}$ upper limit of normal levels). All patients provided written informed consent before enrollment in the study. This protocol was approved by each institution's ethical review board and was conducted in accordance with Good Clinical Practice and the Declaration of Helsinki. The ClinicalTrials.gov Identifier was NCT00933816.

\section{Catheter Placement}

A catheter with anticoagulant coating was inserted through the femoral artery using the Seldinger method. The tip of the catheter with a side hole was placed into the gastroduodenal artery and side hole was located at the common hepatic artery. The gastroduodenal artery and right gastric artery (RGA) were then occluded by metallic embolization coils to prevent gastroduodenal injury from the antitumor agents. The other end of the catheter was connected to an injection port device that was implanted in a subcutaneous pocket in the right femoral area [25, 30](fig.1).

\section{Study Design}

This was a multicenter, open-label, phase I trial. The dose level assignment used a standard 3+3 design with at least three evaluable patients per cohort. Sorafenib was administered orally at a dose of $400 \mathrm{mg}$ twice daily per individual for 28 days in all cohorts. In cohort 1, CDDP was administered at a dose 


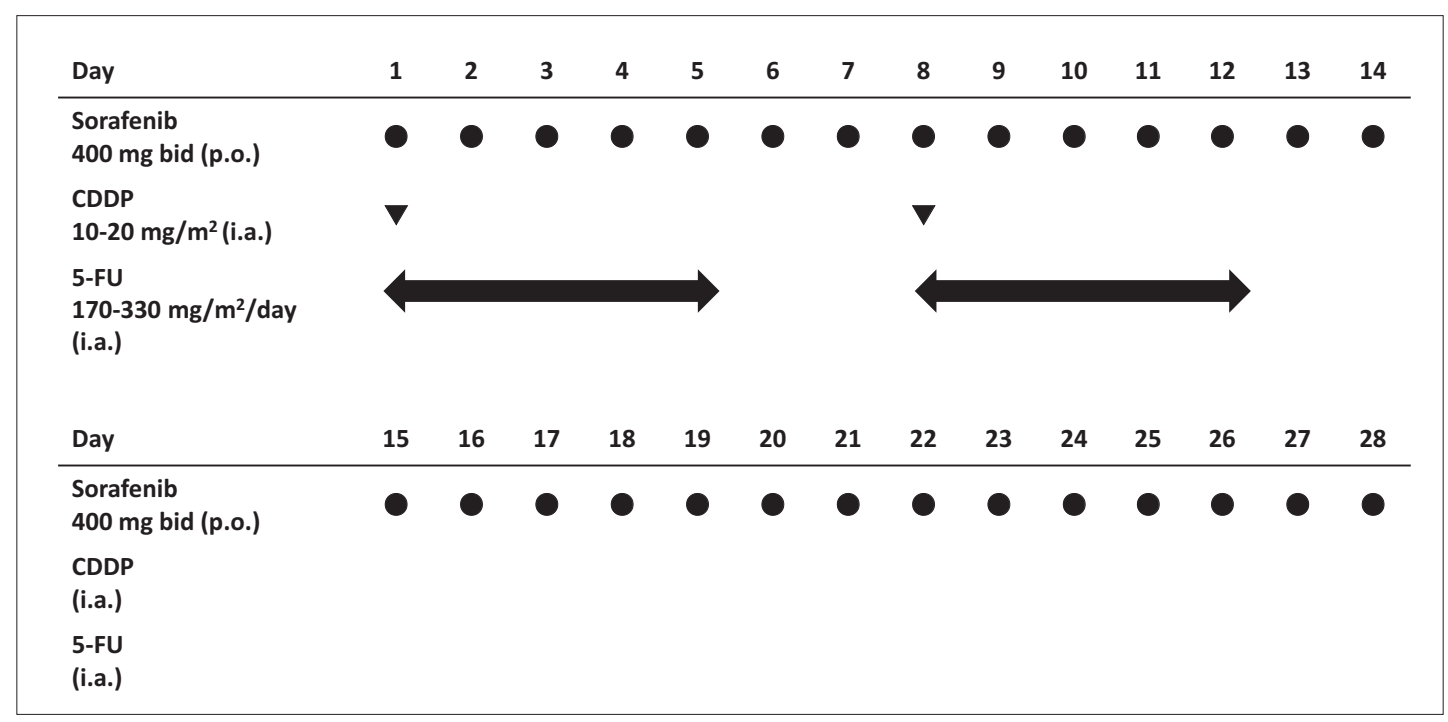

Fig. 2. Protocol of combination therapy. p.o.=per oral; i.a.= intra-arterially.

of $14 \mathrm{mg} / \mathrm{m}^{2}$ on days 1 and 8 , and 5 -FU was administered at a dose of $170 \mathrm{mg} / \mathrm{m}^{2}$ continuously on days 1 to 5 , and days 8 to 12 . In cohorts 2 and 3 , the aforementioned medications frequency of administration was similarly prescribed except that CDDP was used at a dose of $14 \mathrm{mg} / \mathrm{m}^{2}$ and 5-FU was used at a dose of $330 \mathrm{mg} / \mathrm{m}^{2}$ in cohort 2, and CDDP was used at a dose of $20 \mathrm{mg} / \mathrm{m}^{2}$ and 5-FU was used at a dose of $330 \mathrm{mg} /$ $\mathrm{m}^{2}$ in cohort 3 respectively, via the implanted catheter system. A cycle was defined as 28 days and three cycles of combination therapy were continued until a diagnosis of progressive disease (PD) was made or until other withdrawal criteria were met (fig. 2). At the end of each cycle, all AEs were evaluated and the next dose escalation was determined. If one dose limiting toxicity (DLT) was observed in any cohort during cycle 1 , three additional patients were enrolled into the current cohort. If no DLTs were observed, the dose escalations continued.

\section{Outcomes and Assessments}

The primary outcomes of the study were DLT and the secondary outcomes were overall survival (OS), time to progression (TTP), RR, and AE.

The maximum tolerated dose (MTD) was defined as the highest dose level at which less than two patients experienced a DLT in cycle 1 . DLT was defined as grade $\geq 3$ when the patient was febrile $\left(\geq 38.5^{\circ} \mathrm{C}\right)$, or had infection with neutropenia, or leucopenia, or had thrombocytopenia. Grade 4 DLT was defined when there was neutropenia lasting more than 7 days, or; grade 4 thrombocytopenia or when it was necessary to transfuse platelets at the discretion of the treating physician-investigator. Other grade $\geq 3$ manifestations included non-hematologic toxicity excluding rises in amylase and hand-foot skin reactions, and clinically important effects considered drug-related by the physician-investigator (ALT and AST $\geq 10$ times the upper limit of the normal range, serum creatinine $>4$ times the upper limit of the normal range). Grade 4 DLT included hyperamylasemia lasting more than 14 days, with clinically significant pancreatitis including life-threatening type, or causing severe clinical symptoms leading to an interruption of sorafenib for more than 4 weeks.

Safety and efficacy were evaluated based on an intention-to-treat basis. TTP was calculated from study entry to radiological progression according to Response Evaluation Criteria in Solid Tumors (RECIST) version 1.1 and OS was calculated from the date of entry until death due to any cause. Toxicity was graded using the National Cancer Institute Common Terminology Criteria for Adverse Events (version 3.0). Tumor response was assessed by dynamic CT. Baseline tumor status was assessed within 28 days prior to study registration. Physical examination and blood tests including complete blood cell counts, serum chemistry, and urinalysis were carried out at baseline and every week during the treatment. Patients underwent dynamic CT investigations to evaluate tumor responses at the end of each cycle. Tumor evaluation was assessed using RECIST 1.1. 
Table 1. Baseline characteristics of patients with advanced HCC enrolled in this study

\begin{tabular}{|c|c|c|c|c|c|}
\hline & & Cohort 1 & Cohort 2 & Cohort 3 & Total \\
\hline Characteristics & No. of Patients & 6 & 6 & 6 & 18 \\
\hline \multirow[t]{4}{*}{ Age, years } & $50-59$ & 1 & 1 & 2 & 4 \\
\hline & $60-69$ & 4 & 3 & 2 & 9 \\
\hline & $70-79$ & 0 & 3 & 2 & 5 \\
\hline & $80-89$ & 1 & 0 & 0 & 1 \\
\hline \multirow[t]{2}{*}{ PS } & 0 & 6 & 6 & 6 & 18 \\
\hline & 1 & 0 & 0 & 0 & 0 \\
\hline \multirow[t]{3}{*}{ Viral marker } & HBsAg (+) & 2 & 0 & 3 & 5 \\
\hline & HCV-Ab (+) & 3 & 4 & 2 & 9 \\
\hline & Both negative & 1 & 2 & 1 & 4 \\
\hline \multirow[t]{2}{*}{ Child-Pugh score } & 5 & 3 & 4 & 3 & 10 \\
\hline & 6 & 3 & 2 & 3 & 8 \\
\hline \multirow[t]{2}{*}{ Portal vein invasion } & Absent & 5 & 4 & 3 & 12 \\
\hline & Present & 1 & 2 & 3 & 6 \\
\hline \multirow[t]{2}{*}{ Distant metastasis } & Absent & 6 & 6 & 6 & 18 \\
\hline & Present & 0 & 0 & 0 & 0 \\
\hline \multirow[t]{2}{*}{ Stage } & III & 5 & 4 & 3 & 12 \\
\hline & IVA & 1 & 2 & 3 & 6 \\
\hline
\end{tabular}

PS=performance status; HBsAg=hepatitis B virus soluble antigen; HCV-Ab=HCV antibody.

Statistical Analysis

Statistical analysis was performed using IBM SPSS ${ }^{\circledR}$ statistics version 19 (IBM, Armonk, NY, USA). OS and TTP were analyzed using the Kaplan-Meier method.

\section{Results}

\section{Patient Characteristics}

Eighteen patients were evaluated in this study. Across all cohorts, the median age was 67.2 years (range 53-86 years). The majority of patients were male (72.2\%). All patients had a performance status of 0 and were rated as Child-Pugh A. Five patients tested hepatitis B virus surface antigen positive, nine tested hepatitis $\mathrm{C}$ virus (HCV) antibody positive, and four tested negative for both viral markers. Twelve patients had portal vein invasion without extrahepatic spread and were classified as Stage IV-A; six patients without portal vein invasion and extrahepatic spread were considered as Stage III (table 1).

\section{Safety}

Grade 3 erythema multiforme was observed in one patient; and grade 4 thrombocytopenia and grade 3 erythema multiforme were observed in another patient in cohort 1 . The dose of the treatment agents were then escalated to that determined for cohort 2. In that cohort, grade 3 erythema multiforme was observed in one patient. The dose was then escalated to that of cohort 3. In that cohort, no DLT was observed and the MTD was not reached. We determined the recommended dose of the combination to be as follows: sorafenib $400 \mathrm{mg}$ twice daily per individual orally, intra-arterial infusion of CDDP $20 \mathrm{mg} / \mathrm{m}^{2}$ and 5-FU $330 \mathrm{mg} / \mathrm{m}^{2}$ / day (table 2). Other adverse events of non-hematological toxicities (all grade) were hand- 
Table 2. Dosage levels of sorafenib and low-dose FP administered to patients with advanced HCC and DLT

\begin{tabular}{|c|c|c|c|c|c|c|}
\hline Cohort & $\begin{array}{l}\text { Sorafenib } \\
\text { (mg/day) }\end{array}$ & $\begin{array}{l}\text { CDDP } \\
\left(\mathrm{mg} / \mathrm{m}^{2},\right. \\
\text { day } 1,8)\end{array}$ & $\begin{array}{l}5-\mathrm{FU} \\
\left(\mathrm{mg} / \mathrm{m}^{2} / \text { day, }\right. \\
\text { Days 1-5, } \\
\text { Days 8-12) }\end{array}$ & DLT & & Remarks \\
\hline 0 & 800 & 10 & 170 & & & \\
\hline 1 & 800 & 14 & 170 & DLT $2 / 6$ & $\begin{array}{l}\text { EM in } 1 \text { case } \\
\text { PLT and EM } \\
\text { in } 1 \text { case }\end{array}$ & Starting dose \\
\hline 2 & 800 & 14 & 330 & $\begin{array}{l}\text { DLT 1/6 } \\
(\mathrm{EM})\end{array}$ & EM in 1 case & \\
\hline 3 & 800 & 20 & 330 & DLT $0 / 6$ & & Recommended dose \\
\hline
\end{tabular}

$\mathrm{EM}=$ Erythema multiforme; PLT=thrombocytopenia; FP=CDDP+5-FU.

foot skin reactions $(n=11,61.1 \%)$, diarrhea $(n=6,33.3 \%)$, appetite loss $(n=5,27.8 \%)$, and hypertension $(n=4,22.2 \%)$. The treatment-emergent adverse events of hematological toxicities were grade 3 leucopenia $(n=3,16.7 \%)$, grade 3 neutropenia $(n=2,11.1 \%)$, anemia $(n=2$, $11.1 \%)$, and grade 3 thrombocytopenia ( $n=3,16.7 \%$ ) (table 3$)$.

\section{Efficacy}

Seven patients achieved partial response (PR) (3 patients in cohort 1, 1 in cohort 2 and 3 in cohort 3), and seven patients achieved stable disease (SD) (1 patient in cohort 1, 4 in cohort 2 , and 2 in cohort 3), and two patients developed progressive disease (PD). No patients achieved a complete response (CR). Two patients in cohort 1 were not evaluated because of discontinuation caused by erythema multiforme. The RR was $38.9 \%$ and the disease control rate was $77.8 \%$ (table 4). The median TTP was 9.7 months (95\% confidence interval [CI] 5.4-14.0), the median OS was 14.1 months (95\% CI 11.7-16.5) and the 6-month, and 1-year survival rates were $83.3 \%$ and $66.7 \%$, respectively (fig. 3 ).

\section{Discussion}

HAIC is the de facto standard treatment for locally advanced HCC with vascular invasion in Japan. Based on the Japanese HCC clinical practice guidelines [31, 32], HAIC is indicated and recommended for the following tumor status: i) multiple HCC with four or more lesions, ii) HCC with major vascular invasion, or iii) HCC with distant metastasis not considered a prognostic determinant. According to the 18th nationwide survey of the Liver Cancer Study Group of Japan (LCSGJ), chemotherapy is performed only in 5.5\% patients with liver cancer, and approximately $90 \%$ of these patients undergo HAIC [33]. In Japan, CDDP monotherapy [34], low-dose CDDP with 5-FU (low-dose FP) [35], interferon (IFN) with 5-FU [36, 37] and IFN with CDDP and 5-FU [38] are currently used as HAIC regimens. The regimen containing IFN has not become widespread because of the off-label use of this drug. Low-dose FP is the most common regimen used for HAIC and it has demonstrated a favorable outcome in our study with a median survival time (MST) of 15.9 months and a TTP of 4.1 months. A subset of patients who responded to the therapy (CR and PR) exhibited an MST of 40.7 months, while those who did not respond to the therapy (SD and PD) exhibited an MST of just 6.8 months, suggesting a better survival among responders than among non-responders [35]. 







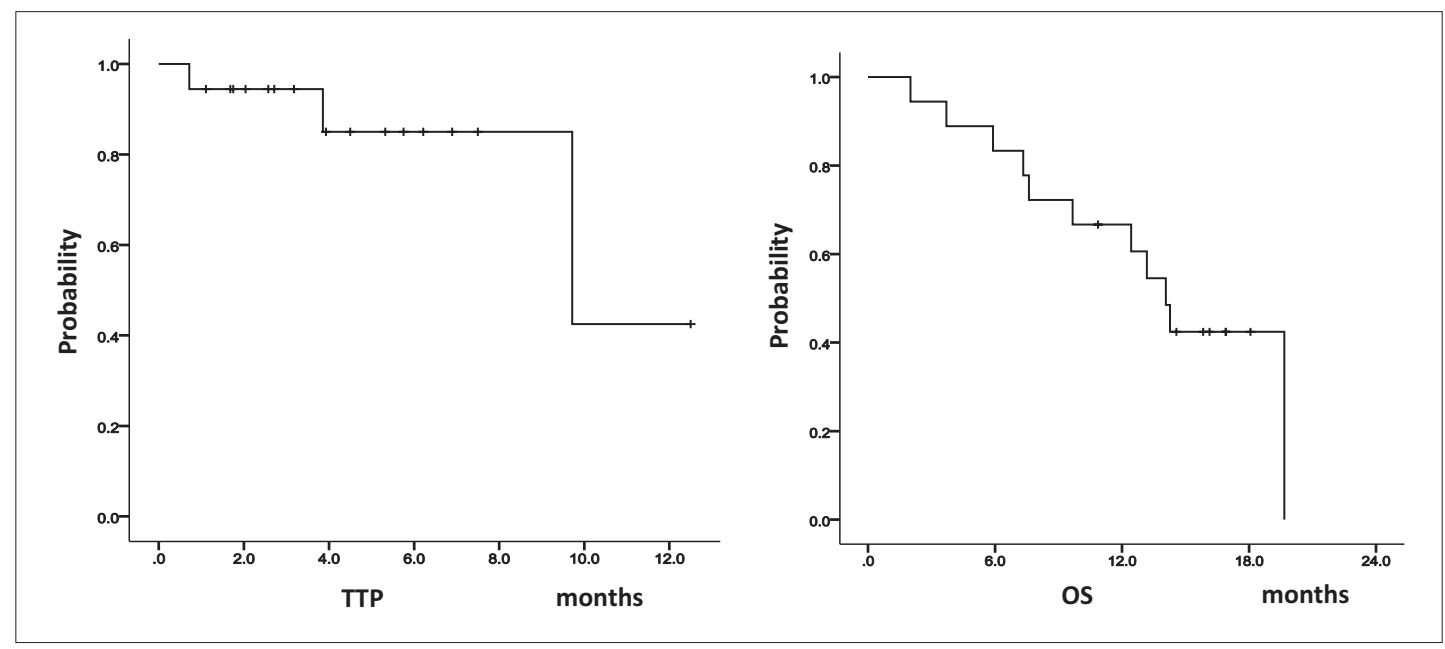

Fig. 3. TTP and OS in 18 patients with HCC treated with sorafenib plus HAIC using low-dose FP. The median TTP was 9.7 months (95\% CI 5.4-14.0), the median OS was 14.1 months (95\% CI 11.7-16.5) and the 6-month survival and 1-year survival were $83.3 \%$ and $66.7 \%$, respectively.

Table 4. Efficacy of sorafenib with HAIC using Low-dose FP

\begin{tabular}{|c|c|c|c|c|}
\hline No. of patients & $\begin{array}{l}\text { Cohort } 1 \\
\text { Sorafenib } 400 \mathrm{mg} \\
\text { twice daily } \\
\text { CDDP } 14 \mathrm{mg} / \mathrm{m}^{2} \\
5 \text {-FU } 170 \mathrm{mg} / \mathrm{m}^{2} \\
(\mathrm{n}=6)\end{array}$ & $\begin{array}{l}\text { Cohort } 2 \\
\text { Sorafenib } 400 \mathrm{mg} \\
\text { twice daily } \\
\text { CDDP } 14 \mathrm{mg} / \mathrm{m}^{2} \\
5 \text {-FU } 330 \mathrm{mg} / \mathrm{m}^{2} \\
(\mathrm{n}=6)\end{array}$ & $\begin{array}{l}\text { Cohort } 3 \\
\text { Sorafenib } 400 \mathrm{mg} \\
\text { twice daily } \\
\text { CDDP } 20 \mathrm{mg} / \mathrm{m}^{2} \\
5 \text {-FU } 330 \mathrm{mg} / \mathrm{m}^{2} \\
(\mathrm{n}=6)\end{array}$ & $\begin{array}{l}\text { Total } \\
(n=18)\end{array}$ \\
\hline
\end{tabular}

Best overall tumor response

\begin{tabular}{|c|c|c|c|c|}
\hline CR & 0 & 0 & 0 & 0 \\
\hline PR & 3 & 1 & 3 & 7 \\
\hline SD & 1 & 4 & 2 & 7 \\
\hline PD & 0 & 1 & 1 & 2 \\
\hline $\mathrm{NE}$ & 2 & 0 & 0 & 2 \\
\hline $\begin{array}{l}\text { Objective response rate } \\
(\mathrm{CR}+\mathrm{PR}), \%\end{array}$ & 50 & 16.7 & 50 & 38.9 \\
\hline $\begin{array}{l}\text { Disease control rate } \\
(\mathrm{CR}+\mathrm{PR}+\mathrm{SD}), \%\end{array}$ & 66.7 & 83.3 & 83.3 & 77.8 \\
\hline
\end{tabular}

$\mathrm{NE}=$ not evaluable.

Propensity analysis of the nationwide survey clearly revealed that HAIC is superior to the best supportive care based on a nationwide survey of the LCSGJ $[39,40]$.

HAIC was developed in Japan but is not used in Western countries because no randomized controlled trials (RCTs) have been conducted, and its use is based on empirical data. The American Association for the Study of Liver Diseases (AASLD) clinical practice guidelines for liver cancer strongly recommends that HAIC should not be used as a standard treatment [41]. To overcome this obstacle, RCTs to prove the survival benefit of HAIC are critical. However, because the effectiveness of empirically established HAIC is widely accepted in Japan, 
to conduct RCTs has been precluded by ethical concerns. This situation resembles that encountered in the history of TACE, which was also empirically developed in Japan but was not approved until RCTs conducted in other countries confirmed its efficacy and safety [10, 42]. The advantage of HAIC is that responses can be estimated on the basis of tumor markers, imaging findings, or other parameters at 2-4 weeks after therapy. Consequently, both responders and non-responders can be distinguished in less than four weeks. For non-responders, treatment should be switched to a molecular targeted therapy such as sorafenib, a global standard of treatment for advanced HCC. There is a growing discussion about whether HAIC or molecular targeted therapy should be selected as the first-line treatment for patients with HCC who are not eligible for TACE, such as with major vascular invasion, and multiple HCCs unresponsive to TACE. For such cases, HAIC generally provides good outcomes with a RR of between $14-71 \%$ and an MST of 2.6-15.9 months [23, 35, 43]. The RR of HAIC in our study was similar to that of previous reports, where the responders demonstrated a better outcome than non-responders. Thus, HAIC should be considered as an alternative option for the treatment of advanced HCC if used appropriately.

The low-dose FP regimen used in this trial was modified from the original study, where one course of HAIC consisted of an intra-arterial infusion of daily CDDP $\left(7 \mathrm{mg} / \mathrm{m}^{2}\right.$ for 1 hour on days $1-5)$ followed by 5 -FU $\left(170 \mathrm{mg} / \mathrm{m}^{2}\right.$ for 5 hours on days $\left.1-5\right)$. Days $6-7$ were a drugfree period and patients received four serial courses of HAIC. However, this method is not suitable for a subset of patients with long hospitalizations or those with frequent injection pain or severe myelosuppression [19]. In addition, the management of HAIC is complicated for medical staff. Therefore, we took a different approach in this trial; CDDP was administered on days 1 and 8 and 5-FU was continuously administered on days 1-5 and days 8-12, aiming to simplify the management and make the treatment more tolerable.

The rationale for this combination therapy is the complementary effects of sorafenib and HAIC, the survival benefit of sorafenib and the tumor shrinkage effect of HAIC. The results of this study showed favorable tumor control by TTP. At our institute, the TTP of sorafenib monotherapy and that of HAIC using low-dose FP was 4.1 months and 5.4 months, respectively. Thus, the TTP of the combination therapy was 9.7 months, indicating an additional effect of combined sorafenib and HAIC compared with sorafenib alone.

All of the adverse events observed were previously known. Hand-foot skin reactions, hypertension, and diarrhea were frequently observed for sorafenib therapy and myelosuppression was observed for HAIC. Previously unknown adverse events emerging from this combination therapy were not observed.

The results of this phase I study were favorable. Therefore, the independent data monitoring committee of this study decided that the phase II study should be cancelled, and they recommended a shift to a phase III trial to confirm the efficacy of the combination therapy.

Currently, a phase III randomized, controlled trial comparing the efficacy of sorafenib alone versus sorafenib in combination with low dose FP in patients with advanced HCC, containing an exploratory study of biomarkers to predict its efficacy, is ongoing (ClinicalTrials. gov ID: NCT01214343).

In conclusion, the recommended dose of this combination therapy was determined to be as follows: sorafenib $400 \mathrm{mg}$ twice daily per individual orally for 28 days with intra-arterial infusion of CDDP $20 \mathrm{mg} / \mathrm{m}^{2}$ on days 1 and 8 and $5-\mathrm{FU} 330 \mathrm{mg} / \mathrm{m}^{2} /$ day continuously on days 1 to 5 , and days 8 to 12 via the implanted catheter system. 


\section{Acknowledgments}

This study was supported by the Japan Liver Oncology Group.

\section{Disclosure Statement}

All authors have no conflicts of interest to declare.

\section{References}

1 Ferlay J, Shin HR, Bray F, Forman D, Mathers C, Parkin DM: Estimates of worldwide burden of cancer in 2008: GLOBOCAN 2008. Int J Cancer 2010;127: 2893-2917.

2 CSIJ: http://ganjoho.jp/pro/statistics/en/backnumber/2013_en.html

3 Bartosch B, Thimme R, Blum HE, Zoulim F: Hepatitis C virus-induced hepatocarcinogenesis. J Hepatol 2009;51:810-820.

4 Belghiti J, Fuks D: Liver resection and transplantation in hepatocellular carcinoma. Liver Cancer. 2012; 1:71-82.

5 Shindoh J, Kaseb A, Vauthey JN. Surgical strategy for liver cancers in the era of effective chemotherapy. Liver Cancer. 2013;2:47-54.

6 Rossi S, Di Stasi M, Buscarini E, Quaretti P, Garbagnati F, Squassante L, Paties CT, Silverman DE, Buscarini L: Percutaneous RF interstitial thermal ablation in the treatment of hepatic cancer. Am J Roentgenol 1996;167:759-768.

7 Buscarini L, Buscarini E, Di Stasi M, Vallisa D, Quaretti P, Rocca A: Percutaneous radiofrequency ablation of small hepatocellular carcinoma: long-term results. Eur Radiol 2001;11:914-921.

8 Lin SM: Local ablation for hepatocellular carcinoma in taiwan. Liver Cancer. 2013;2:73-83.

9 Llovet JM, Real MI, Montaña X, Planas R, Coll S, Aponte J, Ayuso C, Sala M, Muchart J, Solà R, Rodés J, Bruix J, Barcelona Liver Cancer Group: Arterial embolisation or chemoembolisation versus symptomatic treatment in patients with unresectable hepatocellular carcinoma: a randomised controlled trial. Lancet 2002;359:1734-1739.

10 Lo CM, Ngan H, Tso WK, Liu CL, Lam CM, Poon RT, Fan ST, Wong J: Randomized controlled trial of transarterial lipiodol chemoembolization for unresectable hepatocellular carcinoma. Hepatology 2002;35:1164-1171.

11 Lencioni R: Chemoembolization in patients with hepatocellular carcinoma. Liver Cancer. 2012;1: 41-50.

12 Chan SC: Liver transplantation for hepatocellular carcinoma. Liver Cancer. 2013;2: 338-344.

13 Chan SC, Sharr WW, Chan AC, Chok KS, Lo CM: Rescue Living-donor Liver Transplantation for Liver Failure Following Hepatectomy for Hepatocellular Carcinoma. Liver Cancer. 2013;2:332-337.

14 Akamatsu N, Sugawara Y, Kokudo N: Living donor liver transplantation for patients with hepatocellular carcinoma. Liver Cancer. 2014;3:108-118.

15 Llovet JM, Burroughs A, Bruix J: Hepatocellular carcinoma. Lancet 2003;362:1907-1917.

16 Bruix J, Sherman M, Llovet JM, Beaugrand M, Lencioni R, Burroughs AK, Christensen E, Pagliaro L, Colombo M, Rodés J, EASL Panel of Experts on HCC European Association for the Study of the Liver: Clinical management of hepatocellular carcinoma. Conclusions of the Barcelona-2000 EASL conference. J Hepatol 2001;35:421-430.

17 Court WS, Order SE, Siegel JA, Johnson E, DeNittis AS, Principato R, Martz K, Zeiger LS: Remission and survival following monthly intraarterial cisplatinum in nonresectable hepatoma. Cancer Invest 2002;20:613-625.

18 Epirubicin Study Group for Hepatocellular Carcinoma: Intra-arterial administration of epirubicin in the treatment of nonresectable hepatocellular carcinoma. Cancer Chemother Pharmacol 1987;19:183-189.

19 Ando E, Tanaka M, Yamashita F, Kuromatsu R, Yutani S, Fukumori K, Sumie S, Yano Y, Okuda K, Sata M: Hepatic arterial infusion chemotherapy for advanced hepatocellular carcinoma with portal vein tumor thrombosis: analysis of 48 cases. Cancer 2002;95:588-595.

20 Ando E, Yamashita F, Tanaka M, Tanikawa K: A novel chemotherapy for advanced hepatocellular carcinoma with tumor thrombosis of the main trunk of the portal vein. Cancer 1997;79:1890-1896.

21 Itamoto T, Nakahara H, Tashiro H, Haruta N, Asahara T, Naito A, Ito K: Hepatic arterial infusion of 5-fluorouracil and cisplatin for unresectable or recurrent hepatocellular carcinoma with tumor thrombus of the portal vein. J Surg Oncol 2002;80:143-148.

22 Lai YC, Shih CY, Jeng CM, Yang SS, Hu JT, Sung YC, Liu HT, Hou SM, Wu CH, Chen TK: Hepatic arterial infusion chemotherapy for hepatocellular carcinoma with portal vein tumor thrombosis. World J Gastroenterol 2003;9:2666-2670.

23 Okuda K, Tanaka M, Shibata J, Ando E, Ogata T, Kinoshita H, Eriguchi N, Aoyagi S, Tanikawa K: Hepatic arterial infusion chemotherapy with continuous low dose administration of cisplatin and 5-fluorouracil for multiple recurrence of hepatocellular carcinoma after surgical treatment. Oncol Rep 1999;6:587-591. 
24 Tanioka H, Tsuji A, Morita S, Horimi T, Takamatsu M, Shirasaka T, Mizushima T, Ochi K, Kiura K, Tanimoto M: Combination chemotherapy with continuous 5-fluorouracil and low-dose cisplatin infusion for advanced hepatocellular carcinoma. Anticancer Res 2003;23(2C):1891-1897.

25 Toyoda H, Nakano S, Kumada T, Takeda I, Sugiyama K, Osada T, Kiriyama S, Suga T, Takahashi M: The efficacy of continuous local arterial infusion of 5-fluorouracil and cisplatin through an implanted reservoir for severe advanced hepatocellular carcinoma. Oncology 1995;52:295-299.

26 Yodono H, Sasaki T, Tarusawa K, Midorikawa H, Saito Y, Takekawa SD: Arterial infusion chemotherapy for advanced hepatocellular carcinoma using EPF and EAP therapies. Cancer Chemother Pharmacol 1992;31(Suppl):S89-S92.

27 Wilhelm SM, Carter C, Tang L, Wilkie D, McNabola A, Rong H, Chen C, Zhang X, Vincent P, McHugh M, Cao Y, Shujath J, Gawlak S, Eveleigh D, Rowley B, Liu L, Adnane L, Lynch M, Auclair D, Taylor I, Gedrich R, Voznesensky A, Riedl B, Post LE, Bollag G, Trail PA: BAY 43-9006 exhibits broad spectrum oral antitumor activity and targets the RAF/MEK/ERK pathway and receptor tyrosine kinases involved in tumor progression and angiogenesis. Cancer Res 2004;64:7099-7109.

28 Llovet JM, Ricci S, Mazzaferro V, Hilgard P, Gane E, Blanc JF, de Oliveira AC, Santoro A, Raoul JL, Forner A, Schwartz M, Porta C, Zeuzem S, Bolondi L, Greten TF, Galle PR, Seitz JF, Borbath I, Häussinger D, Giannaris T, Shan M, Moscovici M, Voliotis D, Bruix J, SHARP Investigators Study Group: Sorafenib in advanced hepatocellular carcinoma. N Engl J Med 2008;359:378-390.

29 Cheng AL, Kang YK, Chen Z, Tsao CJ, Qin S, Kim JS, Luo R, Feng J, Ye S, Yang TS, Xu J, Sun Y, Liang H, Liu J, Wang J, Tak WY, Pan H, Burock K, Zou J, Voliotis D, Guan Z: Efficacy and safety of sorafenib in patients in the Asia-Pacific region with advanced hepatocellular carcinoma: a phase III randomised, double-blind, placebo-controlled trial. Lancet Oncol 2009;10:25-34.

30 Urabe T, Kaneko S, Matsushita E, Unoura M, Kobayashi K: Clinical pilot study of intrahepatic arterial chemotherapy with methotrexate, 5 -fluorouracil, cisplatin and subcutaneous interferon-alpha-2b for patients with locally advanced hepatocellular carcinoma. Oncology 1998;55:39-47.

31 Kudo M, Izumi N, Kokudo N, Matsui O, Sakamoto M, Nakashima O, Kojiro M, Makuuchi M, HCC Expert Panel of Japan Society of Hepatology: Management of hepatocellular carcinoma in Japan: Consensus-Based Clinical Practice Guidelines proposed by the Japan Society of Hepatology (JSH) 2010 updated version. Dig Dis 2011;29:339-364.

32 Clinical Practice Guidelines for Hepatocellular Carcinoma - The Japan Society of Hepatology 2009 update. Hepatol Res 2010;40(Suppl 1):2-144.

33 Ikai I, Kudo M, Arii S, et al: Report of the 18th follow-up survey of primary liver cancer in Japan. Hepatol Res 2010;40:1043-1059.

34 Yoshikawa M, Ono N, Yodono H, Ichida T, Nakamura H: Phase II study of hepatic arterial infusion of a finepowder formulation of cisplatin for advanced hepatocellular carcinoma. Hepatol Res 2008;38:474-483.

35 Ueshima K, Kudo M, Takita M, Nagai T, Tatsumi C, Ueda T, Kitai S, Ishikawa E, Yada N, Inoue T, Hagiwara S, Minami Y, Chung H: Hepatic arterial infusion chemotherapy using low-dose 5-fluorouracil and cisplatin for advanced hepatocellular carcinoma. Oncology 2010;78(Suppl 1):148-153.

36 Nagano H, Wada H, Kobayashi S, Marubashi S, Eguchi H, Tanemura M, Tomimaru Y, Osuga K, Umeshita K, Doki Y, Mori M: Long-term outcome of combined interferon- $\alpha$ and 5-fluorouracil treatment for advanced hepatocellular carcinoma with major portal vein thrombosis. Oncology 2011;80:63-69.

37 Obi S, Yoshida H, Toune R, Unuma T, Kanda M, Sato S, Tateishi R, Teratani T, Shiina S, Omata M: Combination therapy of intraarterial 5-fluorouracil and systemic interferon-alpha for advanced hepatocellular carcinoma with portal venous invasion. Cancer 2006;106:1990-1997.

38 Yamashita T, Arai K, Sunagozaka H, Ueda T, Terashima T, Yamashita T, Mizukoshi E, Sakai A, Nakamoto Y, Honda M, Kaneko S: Randomized, phase II study comparing interferon combined with hepatic arterial infusion of fluorouracil plus cisplatin and fluorouracil alone in patients with advanced hepatocellular carcinoma. Oncology 2011;81:281-290.

39 Kudo M: Treatment of advanced hepatocellular carcinoma with emphasis on hepatic arterial infusion chemotherapy and molecular targeted therapy. Liver Cancer. 2012;1:62-70.

40 Nouso K, Miyahara K, Uchida D, Kuwaki K, Izumi N, Omata M, Ichida T, Kudo M, Ku Y, Kokudo N, Sakamoto M, Nakashima O, Takayama T, Matsui O, Matsuyama Y, Yamamoto K, Liver Cancer Study Group of Japan: Effect of hepatic arterial infusion chemotherapy of 5-fluorouracil and cisplatin for advanced hepatocellular carcinoma in the Nationwide Survey of Primary Liver Cancer in Japan. Br J Cancer 2013;109:1904-1907.

41 Bruix J, Sherman M, American Association for the Study of Liver Diseases: Management of hepatocellular carcinoma: an update. Hepatology 2011;53:1020-1022.

42 Cammà C, Schepis F, Orlando A, Albanese M, Shahied L, Trevisani F, Andreone P, Craxì A, Cottone M: Transarterial chemoembolization for unresectable hepatocellular carcinoma: meta-analysis of randomized controlled trials. Radiology 2002;224:47-54.

43 Chung YH, Song IH, Song BC, Lee GC, Koh MS, Yoon HK, Lee YS, Sung KB, Suh DJ: Combined therapy consisting of intraarterial cisplatin infusion and systemic interferon-alpha for hepatocellular carcinoma patients with major portal vein thrombosis or distant metastasis. Cancer 2000;88:1986-1991. 